Marie-Ange Somdah, poète, critique, romancier, habite à Boston. Il s'intéresse en particulier au conte africain. Publications: Le Nombril de la Terre (Paris: L'Harmattan, 1994), Campus blues (Paris: Nouvelles du Sud, 1993), Demain sera beau (Paris: Silex, 1989).

\title{
\%
}

\section{Hôtel La Désirade}

A peine sorti de l'avion, une brise murmure à mon oreille. Debout sur la
passerelle, je suis en rade, saisi par une lame d'inspiration subite, enveloppé par une haute vague qui bientôt m'emporte et me laisse choir dans l'immense océan rempli d'encre bleue. Et la muse assidue qui susurre sans cesse en moi depuis la veille. De l'aéroport le taxi jaune-vert se faufile lentement pour partir vers la ville illuminée. Le long de la voie, la vue des cocotiers fait surgir en moi le souvenir inaltérable d'un rire cristallin sur du sable fin.

Chaque jour, je suis dans la ville, arpentant les rues au milieu des nombreux zémidjans, ces taxis-motos comme des libellules virevoltant ça et là, mon tunnel intérieur parfois obstrué par les fumées noires qui vous laissent les yeux irrités en fin de journée. Je marche, les sens aux aguets, tenant dans mon esprit une idée vague d'elle. Les semaines passent, les jours s'écoulent lentement sans que je devine dans toutes les coquettes fleurs aux multiples parfums sa voix qui, elle seule, saura me conduire et m'apaiser l'âme. Oui, je recherche la belle femme noire de mon conte d'enfance que personne ne sait plus conter. Mais nulle part sur les pavés de cette ville, je ne trouve son écho. En désespoir de cause, je pars pour le quartier Jonquet où la nuit venue, Cotonou est belle telle une peau de fauve et chaude tel un buisson ardent. Blotti dans les nichons des belles-de-nuit et grisé par les liqueurs, je dévale une pente pour me retrouver dans une aurore incertaine, le matin venu. Toujours en rade.

J'attends sur la plage, contemplant le doux ressac des vagues écumeuses qui viennent caresser, lécher leur amante, la terre, d'où sourd une chaude exhalaison. J'attends tous les soirs quand la mer a tous les élans poétiques qui sèment à tous les quatre coins les murmures des amoureux savourant un roucoulement sous les cocotiers. La longue attente de cette fiancée invisible me nourrit au quotidien. Je lui dédie à chaque heure de mes loisirs un hymne à sa beauté, elle qui vient de si loin, et pourtant que je devine si près de mes jours arides. Et quand je vois passer là-haut dans le ciel parsemé de nuages le grand oiseau métallique, je ferme les yeux avec la ferme intention de rester en ce lieu bien après la fin de mon contrat afin de la toucher, de la laisser tenir ma main pour une randonnée dans le pays profond. Sirotant ma tasse de thé un soir, au restaurant de l'hôtel, je sens passer une ombre légère qui me regarde avec insistance comme dans une invitation à quelque chose. Je continue de soupirer après la belle femme de mon conte d'enfance. 
Je continue de soupirer après la belle femme de mon conte d'enfance.

Un jour, à l'aube, je vois des pas sur le sable; elles décrivent des lignes de souplesse et de grâce. Accroupi devant la mer, je me laisse bercer par la brise du large. Un crissement se fait entendre; quelqu'un s'approche lentement comme pour ne pas troubler ma méditation matinale. Je me retourne. Elle s'avance encore plus doucement. Parvenue à ma hauteur, elle me sourit. Les genoux dans le sable, elle regarde avec moi l'océan légèrement écumeuse. Un silence sublime plane en moi. J'aperçois une brindille à côté, la prends et la jette dans l'eau. Elle se penche et me souffle quelque chose à l'oreille gauche puis se met debout. Elle passe devant moi, effleure ma peau de ses doigts puis laisse choir son pagne en des gestes lents qui me déséquilibrent. Elle en rit légèrement sous cape. Je la regarde avancer à pas lents, souplesse de ses hanches qui impriment sa beauté sur la plage. Aucun mot, aucune rime pour décrire ce joyau. C'est une splendeur incarnée. Avant de pénétrer dans l'eau, elle me décoche un sourire. Je la regarde se baigner en lentes brassées. Elle me fixe sans arrêt avec ses sourires, les perles rares de mes nuits de tourmente. C'est une discrète et fascinante beauté, là, devant mes yeux. D'où vient-elle?...

Lorsqu'elle sort de l'eau, elle est droite, altière, beauté perlée sur un fond d'horizon aux tons d'aimant. Son pagne noué, toujours dans les mêmes gestes lents qui vous enveloppent tel un encens ensorcelant, elle me souffle quelque chose à l'oreille puis s'en va de son pas lent d'amazone. Elle devient un petit point trouble qui disparaît à l'autre bout de la côte. Le soir, je suis à nouveau une errance inconsolable, habité par un tourbillon, une folle quête impossible. Je regarde à nouveau les jours passer avec leur cortège de mots que je n'arrive pas à semer sur la page blanche pour lire son sourire laissé sur la plage. Et ses mots soufflés à mon oreille. Quel sens leur donner?... Un soir, quelqu'un frappe à ma porte. J'ouvre. Elle est là, majestueuse, avec se sourire magique dessiné par un grand maître. A mon réveil, le lendemain matin, la belle Hausa est partie. Dans mes draps, je la trouve, l'odeur de la femme venue du Nord. Je me mets alors à écrire la poésie de son corps, la poésie de ses hanches, la poésie qui dit son sourire, la poésie qui chante les ondulations au vent de sa silhouette.

Perle rare, fille du Sahel, je te retrouverai dans mes songes. 